\title{
Monitoria inclusiva remota para os alunos com deficiência do IFRO campus Porto Velho Calama/RO
}

\section{Remote inclusive monitoring for students with disabilities at the IFRO Porto Velho Calama/RO campus}

\author{
Lívia Catarina Matoso dos Santos Telles ${ }^{1 *}$, João Guilherme Rodrigues Mendonça ${ }^{1}$
}

\begin{abstract}
RESUMO
A investigação teve por objetivo acompanhar o desenvolvimento de um Programa de Monitoria Inclusiva Remota implementado no IFRO (Instituto Federal de Educação, Ciência e Tecnologia de Rondônia) Campus Porto Velho Calama, nos anos de 2020 e 2021. Para isso buscou-se conhecer os estudantes com deficiência e suas necessidades educacionais específicas (NEEs) através das informações gerenciadas pelo NAPNE (Núcleo de Atendimento às Pessoas com Necessidades Educacionais Específicas), averiguando como foi o processo de seleção dos alunos com deficiência que foram contemplados com o Programa e dos alunos que atuaram como monitores. Os monitores foram selecionados por meio de processos seletivos regidos por editais, sendo que o NAPNE realizou o treinamento e acompanhamento desses monitores. A monitoria ocorreu de forma remota, em que o aluno com NEE e o monitor foram acompanhados por um membro do NAPNE. Através da análise dos dados foi possível constatar que o Programa beneficiou um total de 22 alunos durante 12 meses, sendo mais um instrumento de enfrentamento a evasão.
\end{abstract}

Palavras-chave: Inclusão Educacional; Monitoria Virtual; NAPNE

\section{ABSTRACT}

The research aimed to follow the development of a Remote Inclusive Monitoring Program implemented at the IFRO (Federal Institute of Education, Science and Technology of Rondônia) Porto Velho Calama campus, in the years 2020 and 2021. For that, we sought to know students with disabilities and their specific educational needs (NEEs) through information managed by NAPNE (Service Center for People with Specific Educational Needs), examining the selection process of the students with disabilities who were contemplated by the program and of the students who acted as monitors. The monitors were chosen through selection processes governed by public notices, and NAPNE carried out the training and monitoring of these monitors. Monitoring took place remotely, in which the student with NEE and the monitor were accompanied by a member of NAPNE. Through the analysis of the data, it was possible to verify that the Program benefited a total of 22 students during 12 months, being another instrument to fight school dropping out.

Keywords: Education Inclusive; Virtual Monitoring; NAPNE

\footnotetext{
${ }^{1}$ Universidade Federal de Rondônia (UNIR), Porto Velho, Rondônia, Brasil.

*E-mail: livia.santos@ifro.edu.br
} 


\section{INTRODUÇÃO}

Estudos sobre pessoas com deficiência precisam cada vez mais serem difundidos, há muito o que caminhar no universo da Educação Inclusiva e Educação Especial. Considerando essa questão, este estudo teve como principal objetivo analisar o processo de inclusão de estudantes com deficiência dos cursos das modalidades integrado, subsequente e graduação do campus Porto Velho Calama do IFRO (Instituto Federal de Educação, Ciência e Tecnologia de Rondônia) a partir da atuação do NAPNE (Núcleo de Atendimento às Pessoas com Necessidades Educacionais Específicas) na execução do Programa de Monitoria Inclusiva, visando oferecer aos estudantes melhores condições de aprendizagem e sucesso acadêmico.

Para coleta de dados foram utilizadas planilhas do NAPNE disponíveis nos arquivos digitais do núcleo. Os dados coletados foram transcritos integralmente, categorizados, organizados e apresentados em formato de tabelas.

A inclusão é o termo encontrado para definir uma sociedade que considera todos os seus membros como cidadãos legítimos. O termo inclusão traz a proposta de formação de uma nova escola, consciente da diversidade dos seres humanos. A Educação Inclusiva seria, então, um meio de a escola considerar os cidadãos com deficiência como alunos com capacidades e habilidades a serem desenvolvidas, tal como qualquer outro aluno. Seria o reconhecimento social das diferenças individuais (MADER, 1997).

Ao procurar garantir a inclusão dos alunos com deficiência na educação profissional, reverencia-se que a questão do ensino é uma atividade essencial para a construção da autonomia social. De acordo com Perrenoud (2001) existem inúmeras diferenças que permeiam o espaço escolar e a sociedade no geral e, devido a isto, acreditamos que não se deve esquecer a particularidade de cada sujeito na forma de aprender, de se comunicar, ou na de refletir.

Os alunos são diferentes em suas fisiologias, capacidades perceptiva, manual e gestual, gostos, capacidades criativas, personalidade, em saberes e experiências escolares, em hábitos e modo de vida fora da escola, vestimenta, corpulência, em sexo, origem social, origem religiosa, nacional ou étnica, em sentimentos, projetos, vontades, energias do momento, entre outros (PERRENOUD, 2001). 
Nesta perspectiva é importante valorizar o espaço social, ampliar ações e principalmente, reconhecer que os alunos precisam sonhar, ter oportunidades, não importando qual a sua diferença.

O trabalho desenvolvido nas escolas deve estar voltado para atender todo tipo de diferença, tendo em vista o processo de mudança que vem ocorrendo na sociedade. $\mathrm{O}$ "diferente" torna-se muito mais presente no nosso dia a dia, visto que a cada lugar que frequentamos encontramos alguém diferente, seja com um visual, aparência, sexo, deficiência, cultura, etnia, entre outros. Assim, acredita-se na Educação Profissional os programas educacionais devem estar voltados à diversidade, para que o aluno aprenda a respeitar, viver e se construir nesse contexto.

\section{O PROGRAMA DE MONITORIA INCLUSIVA REMOTA DO IFRO}

O Instituto Federal de Educação, Ciência e Tecnologia de Rondônia (IFRO) é uma autarquia federal vinculada ao Ministério da Educação (MEC). Foi criado por intermédio da Lei $\mathrm{n}^{\circ}$ 11.892, de 29 de dezembro de 2008, que reorganizou a Rede Federal de Educação Profissional, Científica e Tecnológica.

O IFRO tem a missão de promover educação profissional, científica e tecnológica de excelência, por meio da integração entre ensino, pesquisa e extensão, com foco na formação de cidadãos comprometidos com o desenvolvimento humano, econômico, cultural, social e ambiental sustentável (PDI, 2018-2022, p.33).

Entende-se por Monitoria Inclusiva um recurso pedagógico de apoio ao ensino, que possibilita o acompanhamento individual do aluno com Necessidades Educacionais Específicas (NEE), no que se refere aos conteúdos do currículo. A Política de Acesso, Permanência e Êxito do IFRO prevê Programas de atendimento aos estudantes com Necessidades Educacionais Específicas, que têm por finalidade garantir aos/as estudantes com deficiência, transtornos globais do desenvolvimento e altas habilidades ou superdotação, condições específicas que permitam o acompanhamento das atividades de ensino, pesquisa e extensão na Instituição, orientá-los quanto à busca dos seus direitos, visando o combate a discriminações, indiferenças e preconceitos, bem como aquisição de equipamentos de tecnologias assistivas.

A Política de Acesso, Permanência e Êxito do Instituto Federal de Educação, Ciência e Tecnologia de Rondônia (PAPE-IFRO) apresenta um conjunto de princípios, 
diretrizes e objetivos norteadores para a efetivação dos programas, projetos e ações visando ao desenvolvimento do discente e sua preparação para atender aos requisitos da sociedade onde vive e atua como agente de transformação social.

Ressaltamos o papel preponderante da Política de Acesso, Permanência e Êxito do IFRO para a concretude da formação integral do ser humano (IFRO, 2018). O conhecimento experimentado pelo discente no âmbito do IFRO deverá desempenhar papel fundamental para a sua formação integral que transcende as barreiras do mundo do trabalho. A formação do cidadão, assim compreendida, permitirá que o sujeito edifique a sua própria trajetória de vida, numa perspectiva crítica, dialética, autônoma e criativa.

Entre os programas e ações da Política de Acesso, Permanência e Êxito do IFRO há o Programa de Monitoria. Este programa desenvolve-se por meio de atividades de estudantes no apoio aos professores de disciplinas que requeiram contribuição de colaboradores com adequados níveis de conhecimento, habilidades no relacionamento interpessoal e predisposição ao desenvolvimento de planos de trabalho.

Os Programas e Ações Técnico-Científicos, a exemplo da Monitoria, contribuem para a formação intelectual, acadêmica e profissional dos estudantes. O processo seletivo, que inclui editais, estabelecimento de critérios, procedimento para seleção, valores, período de concessão das bolsas e o acompanhamento dos bolsistas, é de responsabilidade das pró-reitorias, diretorias e coordenações a que tais programas se vinculam.

Esta política prevê ainda que as ações serão desenvolvidas pelo Núcleo de Apoio a Pessoas com Necessidades Educativas Específicas (NAPNE). São ações de educação para a diversidade que têm a finalidade de aprofundar as discussões sobre equidade na instituição, oportunizando espaços de reflexão sobre diversidade na mais ampla acepção da palavra e sem qualquer discriminação de etnia, gênero, religião, orientação sexual, idade, entre outras.

Os estudantes com deficiência costumam comentar a respeito do uso de estratégias pedagógicas por parte de alguns professores e a utilização de recursos adaptados, falam também sobre a importância da interação com os colegas. Os profissionais que atuam no NAPNE elencam a importância da formação continuada, buscam conseguir uma carga horária específica para dedicação às atividades do núcleo, a contratação de servidores docentes e técnico administrativos especializados em Educação Inclusiva, tradutores e intérpretes de Libras (Língua Brasileira de Sinais), Cuidadores e a disponibilização de mais recursos materiais para o atendimento das demandas. 
No ano de 2020, o IFRO, por meio da Pró-Reitoria de Ensino (PROEN), publicou o Edital nº 2/2020/REIT - PROEN/IFRO, DE 20 DE JULHO DE 2020 tendo em vista às medidas administrativas diante da Pandemia Covid-19. O edital visava selecionar estudantes bolsistas regularmente matriculados nas modalidades presencial e não presencial dos cursos técnicos e graduações para atuarem como mediadores virtuais no processo de ensino e aprendizagem de estudantes com deficiência e (ou) atendidos pelos NAPNEs.

Teve por objetivo a promoção e a cooperação mútua entre discentes-docentes e discente-discente por meio da mediação virtual aos estudantes com NEE e em suas atividades de ensino, visando ao êxito do processo ensino-aprendizagem.

Tratou-se de um edital que visou ampliar as condições para continuidade das atividades de ensino remota em decorrência da suspensão das atividades presenciais, exclusivamente para os estudantes com deficiência.

O estudante bolsista (mediador virtual), teve as seguintes atribuições: a) Cooperar no atendimento e orientação aos discentes com necessidade educacional específica, visando sua adaptação e maior integração e interação na plataforma virtual de apoio às atividades de ensino remotas ou atividades de ensino correlatas; b) Auxiliar os discentes na realização das atividades propostas pelos docentes na plataforma virtual, sempre que compatível com seu grau de conhecimento e experiência; c) Colaborar com os docentes na identificação de melhorias na execução do processo de ensino, propondo medidas ou recursos alternativos a serem implementados na plataforma virtual ou em atividade de ensino correlatas; d) Apresentar relatório mensal de atividades desenvolvidas e ao final do período de atuação.

\section{DISCUSSÕES E RESULTADOS}

Correia (2008) define os alunos com necessidades educacionais específicas como um grupo abrangente que vai além do público-alvo da Educação Especial, como aqueles que apresentam demandas específicas e podem ter necessidade de utilizar serviços de apoio durante parte ou toda sua trajetória escolar para que tenham suas condições acadêmicas, pessoais e socioemocionais ampliadas.

As condições específicas podem ser de caráter intelectual, desenvolvimental, motor, emocional, sensorial, no processo lógico ou decorrente de problemas de saúde. 
Com a suspensão das aulas presenciais por conta da pandemia de covid-19, claramente aumentaram as dificuldades desses alunos na aprendizagem e nos conteúdos abordados, principalmente nas disciplinas da área técnica. Pôde-se perceber a necessidade de o IFRO rapidamente criar condições para que os alunos tivessem garantidas as adaptações no ambiente remoto.

No ponto de vista de Dorizat (2004) os alunos com NEE passam a ser inseridos no ambiente acadêmico da mesma forma que os alunos considerados "comuns", entretanto a forma na qual a instituição acolhe esses alunos não está devidamente qualificada para todas as individualidades.

Podemos observar na figura abaixo as diferenças nos conceitos de exclusão, segregação, integração e inclusão. Exclusão se trata de deixar de lado, fingir que algo não existe. Segregação significa "separar " as pessoas num só lugar e por último. Na integração as pessoas com deficiência têm de se adequar à sociedade dominante, às suas regras. $\mathrm{Na}$ inclusão é aceitar as diferenças, valorizar cada pessoa, conviver dentro da diversidade humana .

Figura 1. Diferenças entre exclusão, segregação, integração e inclusão
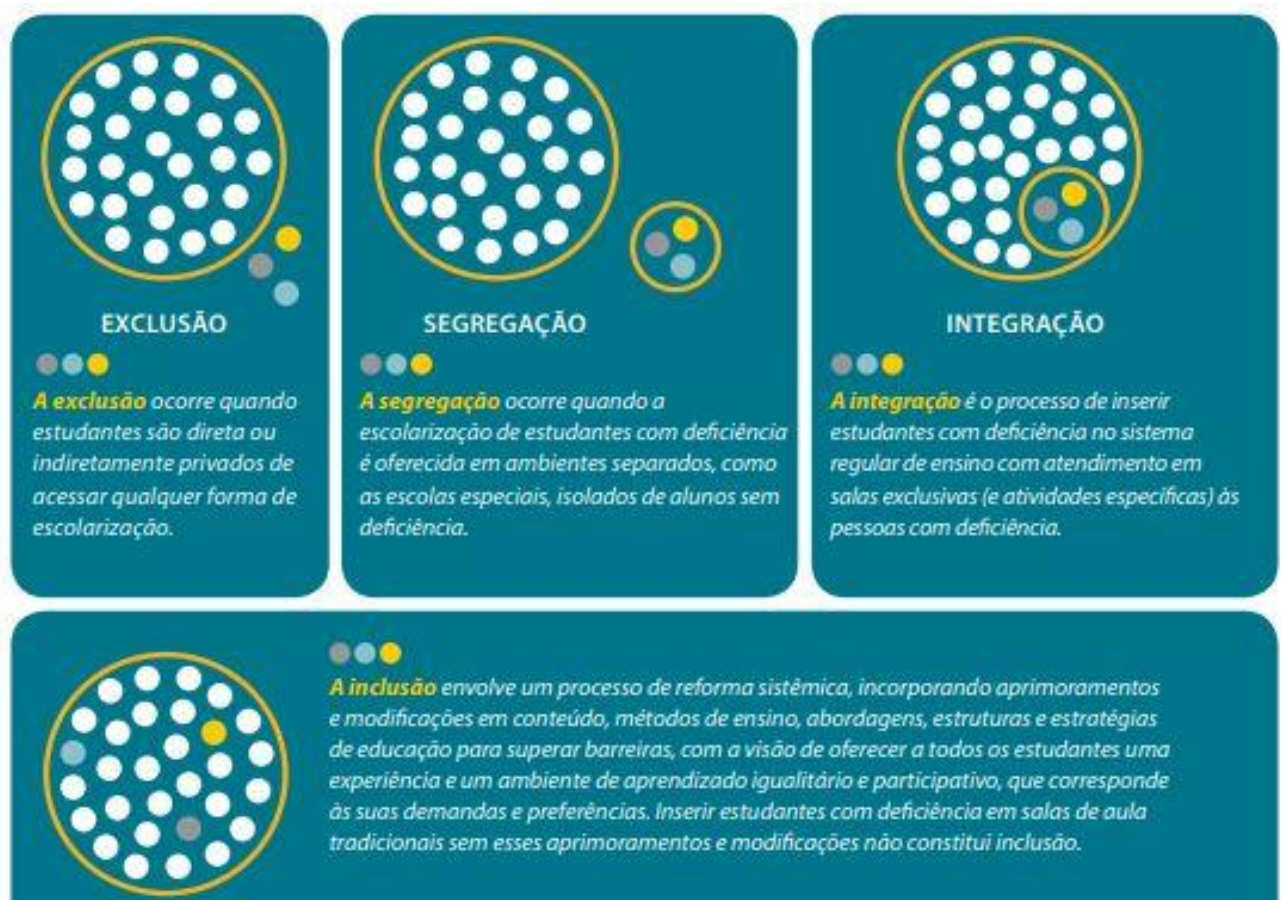

\section{0}

A inclusáo envolve um processo de reforma sistémica, incorporando aprimoramentos e modificoçbes em conteúdo, métodos de ensino, abordagens, estruturas e estratégias de educaçäo para superar barreiras, com a visäo de oferecer a todos os estudantes uma experiència eum ambiente de aprendizado igualitário e participativo, que corresponde às suas demandas e preferencias. Inserir estudantes com deficiéncia em salas de aula tradicionais sem esses aprimoramentos e modificoçōes náo constitui inclusáo. 
Fonte: United Nations Committee on the Rights of Persons with Disabilities ${ }^{2}$ (2015)

No âmbito da educação, a possibilidade de inclusão foi proposta por vários movimentos a favor da inclusão, veio garantir esse direito nas escolas, para que projetos político-pedagógicos sejam implementados com o propósito de dar o direito de acesso, ingresso, e permanência de todos os alunos na escola, independentemente do talento, necessidades específicas, origem socioeconômica ou cultural (STAINBACK, S; STAINBACK, W. 1999).

E por isso, esta pesquisa implementa-se com o intuito de tornar conhecido, principalmente, as necessidades dos alunos com NEE e sua efetiva inclusão no IFRO. Utilizou-se a abordagem qualitativa por acreditar que os sujeitos pesquisados são parte integrante do conhecimento, apresentam um saber prático da realidade, da experiência cotidiana.

A abordagem qualitativa parte do fundamento de que há uma relação dinâmica entre o mundo real e o sujeito, uma "interdependência viva entre o sujeito e o objeto, um vínculo indissociável entre o mundo objetivo e a subjetividade do sujeito" (CHIZZOTI, 2006, p.79).

Realizamos também uma análise quali-quantitativa nos dados institucionais, além de uma descrição e análise dos processos de trabalho do NAPNE do IFRO Campus Porto Velho Calama, no período de maio de 2020 até novembro de 2021, período este caracterizado pela suspensão das aulas presenciais por causa da pandemia de covid-19.

É importante refletir que o conhecimento deve atender as necessidades dos alunos, não os tornar meros objetos de estudos. É preciso entender as causas da falta de preparo da escola ao se deparar com uma pessoa com deficiência

\footnotetext{
${ }^{2}$ Disponível em: https://exponentia.com.br/vamos-falar-sobre-exclusao-segregacao-integracao-e-inclusao/ Acesso em 18/01/2022.
} 
Figura 2. Charge

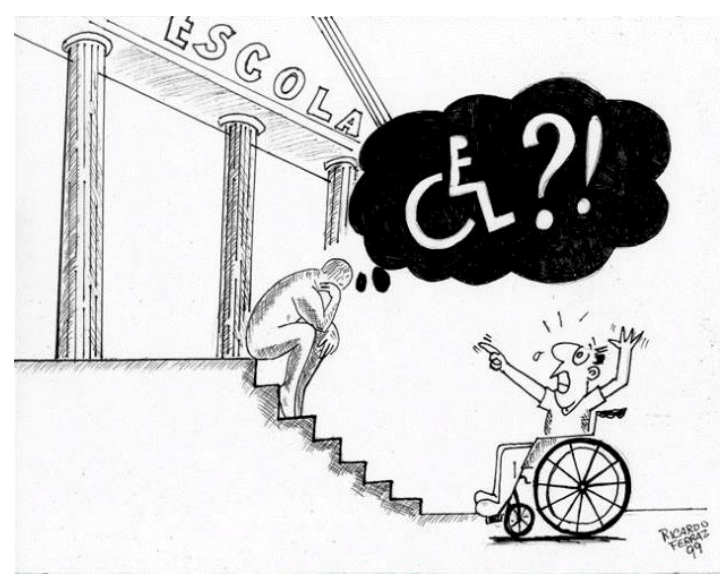

Fonte: Ricardo Ferraz ${ }^{3}$

Nos anos de 2020 e 2021 o NAPNE do Campus Porto Velho Calama abriu vagas para atendimento a 14 alunos com NEE, sendo que os alunos surdos, com Transtorno do Espectro Autista (TEA) e Deficiência Intelectual foram contemplados com 2 monitores cada um.

Quadro 1: Vagas para monitoria do NAPNE do IFRO Campus Porto Velho Calama (2021)

\begin{tabular}{|c|c|}
\hline Necessidade Educacional Específica & Quantidade de vagas para monitores \\
\hline Surdez & 3 \\
\hline Baixa visão & 2 \\
\hline Deficiência intelectual & 2 \\
\hline TGD/TEA* & 5 \\
\hline Deficiência física & 4 \\
\hline Deficiência auditiva & 2 \\
\hline
\end{tabular}

Fonte: NAPNE do IFRO Campus Porto Velho Calama/*Sigla para Transtorno Global do Desenvolvimento/Transtorno do Espectro Autista

Não se pode descartar a importância dos dados quantitativos porque são através deles que mensuramos as ações desenvolvidas, os números reais de alunos com

\footnotetext{
${ }^{3}$ Disponível em: http://www.guiadoeducadorinclusivo.org.br/capitulos/capitulo-7 Acesso em 15/12/2021. Ricardo Ferraz é artista capixaba que tem deficiência física.
} 
necessidades educacionais específicas, catalogamos informações para assim desenvolver as possíveis análises.

Quadro 2: Quantitativo de alunos atendidos por meio remoto no NAPNE do Campus Porto Velho Calama

\begin{tabular}{|c|c|c|c|}
\hline $\begin{array}{l}\text { Quant. de } \\
\text { alunos } \\
\text { atendidos }\end{array}$ & $\begin{array}{c}\text { Tipos de } \\
\text { deficiência }\end{array}$ & Curso do aluno & Situação \\
\hline 1 & Surdez & $\begin{array}{l}2^{\circ} \text { ano de Informática Matutino } \\
\text { (modalidade Integrado) }\end{array}$ & $\begin{array}{c}\text { Recebeu apoio } \\
\text { da Monitora }\end{array}$ \\
\hline \multirow[t]{2}{*}{3} & \multirow[t]{2}{*}{ Baixa Visão } & $\begin{array}{c}2^{\circ} \text { ano de Informática Matutino } \\
\text { (modalidade Integrado) }\end{array}$ & \multirow[t]{2}{*}{$\begin{array}{c}\text { Recebeu apoio } \\
\text { da Monitora }\end{array}$} \\
\hline & & Informática/matutino $/ 1^{\circ}$ ano & \\
\hline 1 & $\begin{array}{c}\text { Deficiência } \\
\text { Intelectual }\end{array}$ & $\begin{array}{c}1^{\circ} \text { ano de Informática Matutino } \\
\text { (modalidade Integrado) }\end{array}$ & $\begin{array}{c}\text { Recebeu apoio } \\
\text { da Monitora }\end{array}$ \\
\hline \multirow{4}{*}{4} & \multirow{4}{*}{ TGD/TEA } & $\begin{array}{c}2^{\circ} \text { ano Informática Matutino } \\
\text { (modalidade Integrado) }\end{array}$ & \multirow{4}{*}{$\begin{array}{c}\text { Recebeu apoio } \\
\text { da Monitora }\end{array}$} \\
\hline & & $\begin{array}{c}1^{\circ} \text { ano de Informática Vespertino } \\
\text { (modalidade Integrado) }\end{array}$ & \\
\hline & & $\begin{array}{c}2^{\circ} \text { ano matutino de Eletrotécnica } \\
\text { (modalidade Integrado) }\end{array}$ & \\
\hline & & $\begin{array}{c}1^{\circ} \text { ano Informática Matutino } \\
\text { (modalidade Integrado) }\end{array}$ & \\
\hline \multirow{6}{*}{6} & \multirow{6}{*}{$\begin{array}{l}\text { Deficiência } \\
\text { física }\end{array}$} & Edificações/ matutino/ $1^{\circ}$ & \multirow{6}{*}{ Sem monitoria } \\
\hline & & Edificações/vespertino/ $3^{\circ}$ ano & \\
\hline & & Eletrotécnica/matutino/ $3^{\circ}$ ano & \\
\hline & & Química/vespertino/2o ano & \\
\hline & & Informática/matutino $/ 1^{\circ}$ & \\
\hline & & Informática/matutino $/ 1^{\circ}$ & \\
\hline \multirow{3}{*}{3} & \multirow{3}{*}{$\begin{array}{l}\text { Deficiência } \\
\text { auditiva }\end{array}$} & $1^{\circ}$ eletrotécnica subsequente & \multirow{3}{*}{ Sem monitoria } \\
\hline & & $1^{\circ}$ período ADS & \\
\hline & & Química/vespertino $/ 2^{\circ}$ ano & \\
\hline
\end{tabular}


Total de alunos com NEE atendidos: 9

Fonte: NAPNE do IFRO Campus Porto Velho Calama

Quando se trata de acessibilidade pedagógica, não diz respeito apenas ao ensino de alunos com deficiência, ela pressupõe um conjunto de possibilidades que buscam ampliar a aprendizagem de alunos como um todo. Durante a educação remota foi preciso averiguar as distinções entre acompanhamento, atendimento e apoio, tendo em vista principalmente que os alunos NEE que tinham o acompanhamento de Cuidador ou Tradutor e Intérprete de LIBRAS precisou ser alterado.

A seleção dos monitores ocorreu através do edital $n^{\circ}$ 2/2020/REIT PROEN/IFRO, de 20 de julho de 2020 e edital n 1/2021/REIT - PROEN/IFRO, de 14 de abril de 2021. Ao final os monitores cumpriram as seguintes cargas horárias no Programa:

Quadro 3. Carga horária da monitoria inclusiva

\begin{tabular}{|c|c|}
\hline Quantitativo de monitores & Carga horária da monitoria \\
\hline Monitor 1 & 230 horas \\
\hline Monitor 2 & 230 horas \\
\hline Monitor 3 & 96 horas \\
\hline Monitor 4 & 230 horas \\
\hline Monitor 5 & 230 horas \\
\hline Monitor 6 & 200 horas \\
\hline Monitor 7 & 96 horas \\
\hline Monitor 8 & 230 horas \\
\hline Monitor 9 & 230 horas \\
\hline Monitor 10 & 230 horas \\
\hline Monitor 11 & 230 horas \\
\hline Monitor 12 & 230 horas \\
\hline Monitor 13 & 230 horas \\
\hline Monitor 14 & 230 horas \\
\hline Monitor 15 & 230 horas \\
\hline Monitor 16 & 138 horas \\
\hline Monitor 17 & 106 horas \\
\hline
\end{tabular}

Fonte: NAPNE do IFRO Campus Porto Velho Calama 
No total, foram necessários 13 profissionais membros do NAPNE para acompanhar o desenvolvimento das monitorias inclusivas. A equipe do NAPNE é multidisciplinar, realiza atendimentos e acompanhamentos ao aluno, como também atende as demandas da instituição, auxiliando nos projetos de acessibilidade arquitetônica e educacional. Todas as atividades realizadas pelo NAPNE são de cunho inclusivo, com o intuito de trazer informação e formação para a comunidade escolar.

A equipe do NAPNE do Campus Porto Velho Calama, no ano de 2021, foi formada pelos seguintes profissionais: três pedagogas, sendo duas Orientadoras Educacionais e uma Pedagoga professora da graduação, duas Assistentes de Alunos, quatro Tradutores e Intérpretes de LIBRAS, um Tradutor e Revisor de Braille, uma Cuidadora, cinco professores, um Enfermeiro e um Assistente Social. Neste ano a equipe atendeu um total de 22 alunos.

Quadro 4. Profissionais do NAPNE que atuaram como orientadores no Programa de Monitoria

\begin{tabular}{c|c} 
Nome & $\begin{array}{c}\text { Carga horária da } \\
\text { monitoria } \\
\text { Orientador 1 }\end{array}$ \\
\hline Orientador 2 horas \\
\hline Orientador 3 & 80 horas \\
\hline Orientador 4 & 80 horas \\
\hline Orientador 5 & 120 horas \\
\hline Orientador 6 & 120 horas \\
\hline Orientador 7 & 80 horas \\
\hline Orientador 8 & 80 horas \\
\hline Orientador 9 & 80 horas \\
\hline Orientador 10 & 40 horas \\
\hline Orientador 11 & 80 horas \\
\hline Orientador 12 & 80 horas \\
\hline Orientador 13 & 40 horas \\
\hline
\end{tabular}

Fonte: NAPNE do IFRO Campus Porto Velho Calama 
A Educação Inclusiva não exclui a possibilidade de existir uma Educação Especial, desde que ocorram em paralelo. Inclusive, a Educação Inclusiva depende da existência de suportes especializados, na formação de profissionais especialistas em diferentes tipos de necessidades especiais e de ensino.

$\mathrm{Na}$ rede estadual e municipal de educação existe o Atendimento Educacional Especializado (AEE), sendo ofertado no turno inverso ao da classe comum. O AEE auxilia no processo de ensino aprendizado do aluno com NEE, sendo desenvolvido por um profissional especializado que verifica as barreiras para a aprendizagem e adequa materiais, formas de se trabalhar e ambientes que favoreçam o ensino para o aluno em questão, que será observado pelo educador do ensino regular deste aluno, trabalhando em parceria com o AEE. Já nos Institutos Federais que compõem a rede federal de educação, existem os NAPNES.

\section{CONSIDERAÇÕES FINAIS}

A pesquisa revelou como ocorreu o desenvolvimento da política de inclusão no IFRO Campus Porto Velho Calama, apresentando os desafios, limites e possibilidades na implementação do Programa de Monitoria Inclusiva Remota. Verificamos e sistematizamos as ações realizadas pela equipe do NAPNE, unificando dados e possibilitando esclarecimentos e disseminação da Educação Inclusiva.

Observamos que houve o acompanhamento de alunos com deficiência através da monitoria, com a participação dos monitores e alunos com deficiência em eventos, em busca de encorajar os discentes a se identificarem com suas deficiências, ajudando a superar seus limites e garantir o acesso e permanência no ensino técnico e tecnológico

Houve uma melhoria no desempenho escolar de discentes com deficiência, com um percentual de aprovação maior em relação ao período de início da pandemia, sendo que houve apenas um aluno que solicitou transferência e não concluiu o curso.

\section{AGRADEDIMENTOS}

Ao IFRO Campus Porto Velho Calama

A Pró-Reitoria de Pesquisa, Inovação e Pós-graduação (PROPESP) do IFRO

Ao Grupo de Pesquisa GPDIN - Grupo de Pesquisa em Diversidade, Acessibilidade e Educação Inclusiva 


\section{REFERÊNCIAS}

BRASIL. Lei no 11.892, de 29 de dezembro de 2008. Institui a Rede Federal de Educação Profissional, Científica e Tecnológica, cria os Institutos Federais de Educação, Ciência e Tecnologia, e dá outras providências. Disponível em: http://www.planalto.gov.br/ccivil_03/_ato2007-2010/2008/lei/111892.htm Acesso em 02/12/2021.

BRASIL. Ministério da Educação. Concepção e Diretrizes, Instituto Federal de Educação, Ciência e Tecnologia. PDE. Brasília, 2008

CHIZZOTTI, Antônio. Pesquisa em ciências humanas e sociais. 8 ed. São Paulo: Cortez, 2006

CORREIA, L. Inclusão e Necessidades educativas Especiais - Um guia para Educadores e Professores. 2. ed. Porto, Portugal. Porto Editora, 2008.

DORIZAT, A. (2004). Educação De Surdos No Ensino Regular: Inclusão Ou Segregação? Revista do Centro de Educação Especial, n.24, 2004.

https://periodicos.ufsm.br/educacaoespecial/article/view/4921/2955.

IFRO. Plano de Desenvolvimento Institucional IFRO 2018-2022. Disponível em https://portal.ifro.edu.br/images/ifro-pdi-interativo-20180209_pagina-simples.pdf. Acesso em 02 de março de 2021.

IFRO. RESOLUÇÃo No 26/ PAPE - Política de Acesso, Permanência e Êxito do Instituto Federal de Educação, Ciência e Tecnologia de Rondônia - IFRO.

Disponível em: https://portal.ifro.edu.br/images/Proreitorias/Proen/Resolu\%C3\%A7\%C3\%A3o_n\%C2\%BA_26_-_PAPE__Pol\%C3\%ADtica_de_Acesso_Perman\%C3\%AAncia_e_\%C3\%8Axito.pdf. Acesso em 01/01/2022.

MADER, Gabrielle. Integração da pessoa portadora de deficiência: a vivência de um novo paradigma. São Paulo, Memnon, 1997.

PERRENOUD, Philippe. A pedagogia na escola das diferenças: fragmentos de uma sociologia do fracasso. Porto Alegre: Artmed Editora, 2001.

STAINBACK, W., \& STAINBACK, S. Inclusão Um Guia Para Educadores. PORTO ALEGRE: ARTMED, 1999. 